\title{
Late incidence and recurrence of new-onset atrial fibrillation after isolated surgical aortic valve replacement
}

Rikhard Björn, MD, ${ }^{a}$ Maunu Nissinen, MD, ${ }^{\mathrm{b}}$ Joonas Lehto, MD, PhD, ${ }^{\mathrm{a}}$ Markus Malmberg, MD, PhD, Fredrik Yannopoulos, MD, PhD ${ }^{\mathrm{c}}{ }^{\mathrm{K}}$ K. E. Juhani Airaksinen, MD, PhD, ${ }^{\mathrm{a}}$ Juha E. K. Hartikainen, MD, PhD, Tuomo Nieminen, MD, PhD, ${ }^{\mathrm{d}, \mathrm{e}}$ Fausto Biancari, MD, PhD, ${ }^{\mathrm{a}, \mathrm{c}}$ Jarmo Gunn, MD, PhD, ${ }^{\mathrm{a}}$ and Tuomas O. Kiviniemi, MD, PhD, FESC ${ }^{\text {a,f }}$

\section{ABSTRACT}

Objectives: Atrial fibrillation (AF) is a common complication after cardiac surgery. More knowledge is needed about long-term AF recurrence and adverse outcomes related to new-onset AF (NOAF) during the index hospitalization.

Methods: A total of 1073 patients underwent isolated surgical aortic valve replacement at the 4 participating hospitals (2002-2014). After the exclusion of patients with a history of any preoperative AF, the final study population included 529 patients in the bioprosthetic and 253 patients in the mechanical valve prosthesis cohort. Median follow-up time was 5.4 (interquartile range, 3.4-8.2) years in the combined cohort.

Results: Altogether 333 (42.6\%) patients had in-hospital NOAF and 250 (32.0\%) AF after hospital discharge. In the mechanical cohort, $64(25.3 \%)$ experienced inhospital NOAF and $74(29.2 \%)$ AF after hospital discharge, whereas in the bioprosthetic cohort, $269(50.9 \%)$ patients had in-hospital NOAF and $176(33.3 \%)$ AF after hospital discharge. Patients with NOAF during the index hospital stay had a multifold risk of AF after hospital discharge in the combined cohort (hazard ratio $[\mathrm{HR}], 3.68 ; 95 \%$ confidence interval $[\mathrm{Cl}], 2.82-4.81 ; P<.0001)$ as well as in both cohorts separately (bioprosthetic: HR, 4.35; 95\% Cl, 3.05-6.22; $P<.001$; mechanical: $\mathrm{HR}, 2.54 ; 95 \% \mathrm{Cl}, 1.59-4.03 ; P<.001$ ). Patients with an in-hospital NOAF also had a significantly higher adjusted risk of death during the follow-up in the mechanical $(\mathrm{HR}, 2.05 ; 95 \% \mathrm{Cl}, 1.10-3.82 ; P=.025)$ and bioprosthetic (HR, 1.63; $95 \% \mathrm{Cl}, 1.17-$ 2.28; $P=.004)$ valve prosthesis cohorts.

Conclusions: NOAF during the index hospitalization is associated with a 2- to 4 -fold risk of later AF and 1.6- to 2.0-fold risk of all-cause mortality after mechanical and bioprosthetic surgical aortic valve replacement. (J Thorac Cardiovasc Surg 2022;164:1833-43)

New-onset atrial fibrillation (NOAF) is very common after cardiac surgery and has an overall incidence of $31 \%$ to $74 \% .^{1-7}$ The incidence of NOAF is significantly higher after surgical aortic valve replacement (SAVR) compared with coronary artery bypass grafting ${ }^{5}$ or transcatheter aortic valve implantation. ${ }^{8}$ There are only a few studies concerning

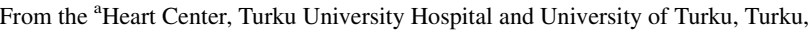

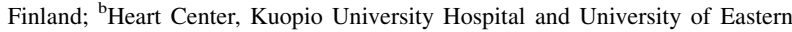
Finland, Kuopio, Finland; ${ }^{\mathrm{c}}$ Department of Surgery, Oulu University Hospital and University of Oulu, Oulu, Finland; ${ }^{\mathrm{d}}$ Department of Internal Medicine, Helsinki University Hospital and University of Helsinki, Helsinki, Finland; ${ }^{\mathrm{e}}$ Department of Internal Medicine, South Karelia Central Hospital, Lappeenranta, Finland; and ${ }^{\mathrm{f}}$ Division of Cardiovascular Medicine, Brigham and Women's Hospital and Harvard Medical School, Boston, Mass.

Funding for this work was received from Finnish Medical Foundation, the Finnish Foundation for Cardiovascular Research, Helsinki, Finland; State Clinical Research Fund (EVO) of Turku University Hospital, Turku, Finland; the Emil
}

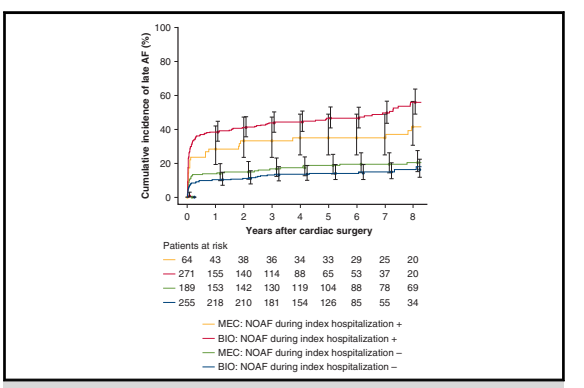

Occurrence of late atrial fibrillation after surgical aortic valve replacement.

CENTRAL MESSAGE

NOAF detected during index

hospitalization appeared to be a strong biomarker of later AF and all-cause mortality after bioprosthetic and mechanical SAVR in a median 5.4-year follow-up.

\begin{abstract}
PERSPECTIVE
Patients experiencing NOAF during hospital stay after SAVR are prone to the recurrence of AF later in life. Patients with NOAF and risk factors for stroke might be considered candidates for permanent OAC.
\end{abstract}

See Commentaries on pages 1844 and 1845 . the association of NOAF with late atrial fibrillation (AF) and long-term mortality in SAVR patients. ${ }^{9-11}$ In a recent singlecenter prospective study concerning patients undergoing SAVR, patients with NOAF had a ninefold increased risk of developing symptomatic late AF. ${ }^{9}$ However, especially within the group of patients entering mechanical SAVR,
Aaltonen Foundation; the Maud Kuistila Foundation; and an unrestricted grant from Bristol-Myers-Squibb-Pfizer.

Received for publication Sept 4, 2020; revisions received March 23, 2021; accepted for publication March 24, 2021; available ahead of print April 9, 2021.

Address for reprints: Tuomas O. Kiviniemi, MD, PhD, FESC, Heart Center, Turku

University Hospital and University of Turku, POB 52, FI-20521, Turku, Finland (E-mail: tuoski@utu.fi).

0022-5223

Copyright (C) 2021 The Authors. Published by Elsevier Inc. on behalf of The American Association for Pediatric Ophthalmology and Strabismus. This is an open access article under the CC BY license (http://creativecommons.org/licenses/by/4.0/). https://doi.org/10.1016/j.jtcvs.2021.03.101 


$\begin{aligned} \text { Abbreviations and } & \text { Acronyms } \\ \mathrm{AF} & \text { atrial fibrillation } \\ \mathrm{CHA}_{2} \mathrm{DS}_{2} \text {-VASc }= & \text { Congestive heart failure, } \\ & \text { Hypertension, Age } \geq 75 \text { years, } \\ & \text { Diabetes mellitus, Stroke, } \\ & \text { Vascular disease, Age } 65- \\ & 74 \text { years, Sex category (female) } \\ = & \text { confidence interval } \\ \mathrm{CI} & =\text { electrocardiogram } \\ \mathrm{ECG} & =\text { European System for Cardiac } \\ \text { EuroSCORE } & \text { Operative Risk Evaluation } \\ \mathrm{HR} & \text { hazard ratio } \\ \mathrm{INR} & \text { international normalized ratio } \\ \text { Lasso } & \text { least absolute shrinkage and } \\ & \text { selection operator } \\ \mathrm{NOAF} & =\text { new-onset atrial fibrillation } \\ \mathrm{SAVR} & =\text { surgical aortic valve } \\ & \text { replacement } \\ \text { TIA } & \text { transient ischemic attack } \\ \text { VKA } & \text { vitamin K antagonist }\end{aligned}$

\begin{tabular}{|l}
\hline Scanning this QR code will \\
take you to the table of con- \\
tents to access supplementary \\
information.
\end{tabular}

the data on the recurrence of $\mathrm{AF}$ are scarce. In addition, although the association of NOAF and higher mortality has been previously reported in patients undergoing SAVR and CABG procedures, ${ }^{5,11,12}$ there are few studies on the influence of NOAF on mortality and other adverse events in patients receiving permanent anticoagulation, ${ }^{12}$ such as the ones undergoing mechanical SAVR.

The aim of this multicenter study was to evaluate the incidence and association between in-hospital NOAF and late $\mathrm{AF}$ after hospital discharge during long-term follow-up in patients with bioprosthetic and mechanical isolated SAVR, therefore providing practical information on the recurrence of AF in differently selected patient groups. In addition, we sought to evaluate the effect of in-hospital NOAF on cerebrovascular events and mortality in each patient cohort separately.

\section{METHODS \\ Data Collection}

The Consortium of Studies in the Field of Atrial Fibrillation, Stroke, and Bleeding in Patients Undergoing Aortic Valve Replacement (CAREAVR; ClinicalTrials.gov Identifier: NCT02626871) is a Finnish multicenter retrospective study on the rate of $\mathrm{AF}$, thromboembolic complications, and bleeding events in patients undergoing isolated bioprosthetic or mechanical SAVR. The data are collected as part of a broader ongoing protocol in Finland to evaluate the thromboembolic and bleeding complications of AF management in patients undergoing cardiac procedures. ${ }^{13,14}$

The study group comprised patients who underwent isolated bioprosthetic SAVR in the cardiac surgery units of 4 Finnish university hospitals (Helsinki, Turku, Oulu, and Kuopio) over the period from 2002 to 2014 (in Helsinki 2006-2014) and an isolated mechanical SAVR in Turku University Hospital cardiac surgery unit over the same time period. In addition, patients undergoing isolated mechanical SAVR in Oulu university hospital over the period from 2002 to 2014 were included in the mortality analyses but were excluded from other analyses because of the lack of follow-up information on other outcome events. Patients who underwent any other major concomitant cardiac surgery procedure or had a history of AF before the surgery were excluded from this study.

The data were retrospectively collected from electronic patient records. To obtain reliable and accurate follow-up data, only patients from the catchment area of each study hospital were included in this study. Patient records were individually reviewed with a standardized structured data collection protocol for pre- and perioperative data, discharge data, and long-term follow-up events such as NOAF, stroke, transient ischemic attack (TIA), bleeding events, and mortality. The end points of this prespecified study included the occurrence of NOAF during the index hospitalization as well as the occurrence of $\mathrm{AF}$, stroke, and death during the follow-up after discharge.

The causes of death were derived from Statistics Finland. This governmental office monitors the time and causes of death in the whole of Finland. This allows the tracking of deaths even if the person moves to another hospital region resulting in a longer follow-up for mortality compared with the other end points.

During the period under study, the routine perioperative anticoagulation practice for mechanical and bioprosthetic aortic valve replacement was enoxaparin 40 to $60 \mathrm{mg}$ given subcutaneously once a day starting in the evening of the day of the surgery and continuing until vitamin $\mathrm{K}$ antagonist (VKA) treatment (started on the first postoperative day) reached the therapeutic level (international normalized ratio $[I N R], \geq 2.0$ ) at all sites. For the bioprosthetic cohort, the routine duration of anticoagulation after surgery was 90 days. The need for permanent oral anticoagulation after the 90 days was evaluated individually by the treating physician, on the basis of the AF burden and the total risk of cerebral infarction assessed according to the Congestive heart failure, Hypertension, Age $\geq 75$ years, Diabetes mellitus, Stroke, Vascular disease, Age 65-74 years, Sex category (female) $\left(\mathrm{CHA}_{2} \mathrm{DS}_{2}\right.$-VASc) score. ${ }^{15,16}$ In the mechanical patient cohort, all patients were treated with permanent VKAs. In the mechanical cohort 22 patients received the On-X valve (CryoLife Inc, Kennesaw, Ga), which demanded routine VKA treatment with an INR target of 2.0 to 3.0 for the first 3 months. After 3 months, selected On-X (CryoLife Inc) patients had VKA treatment with an INR target of 1.8 to 2.0 combined with aspirin $100 \mathrm{mg}$ once daily. In both cohorts, preoperative $\beta$-blocker medication was routinely sustained beyond the surgery. No other antiarrhythmic prophylaxis was routinely used.

The diagnosis of in-hospital NOAF was confirmed using a 12-lead electrocardiogram (ECG) recording or telemonitoring indicating an $\mathrm{AF}$ episode of 10 minutes or longer. Late $\mathrm{AF}$ was defined as $\mathrm{AF}$ after hospital discharge during follow-up and was confirmed using a 12-lead ECG recording or telemonitoring indicating an $\mathrm{AF}$ episode of 10 minutes or longer. The $\mathrm{AF}$ episodes appearing during the index hospitalization and continuing after hospital discharge were not defined as late $\mathrm{AF}$ if the rhythm converted to sinus rhythm either spontaneously or with cardioversion within 3 months after the index surgery. The patients remaining in new permanent AF after 3 months were included in late AF group and were therefore classified as AF after discharge. Patients with in-hospital NOAF were treated with either cardioversion or antiarrhythmic drugs depending on the evaluation of the treating physician. The routine treatment for hemodynamically unstable patients was early electrical cardioversion, and in other patients the treatment line depended on the patients' symptoms and response to rate control. Ischemic stroke was defined as a permanent focal neurological deficit adjudicated by a neurologist and confirmed via computed tomography or 
magnetic resonance imaging. Only patients with ischemic strokes considered definite by the treating neurologist or physician were included in the present study. Subtypes of ischemic strokes were categorized by treating physicians using the Trial of Org 10172 in Acute Stroke Treatment (TOAST) classification system. ${ }^{17}$ Major stroke was defined according to the aforementioned definitions, excluding lacunar strokes $(<20 \mathrm{~mm}$ in diameter).

Urgent operation was defined as an operation performed during the same in-hospital stay, emergency operation as an operation before the next working day, and salvage procedure as an operation in which patients require cardiopulmonary resuscitation en route to the operating theatre or before the induction of anesthesia. Previous cardiac surgery was defined as one or more previous major cardiac operation involving opening the pericardium. Left atrium dilatation was defined as atrial anteroposterior diameter $>38 \mathrm{~mm}$ in women and $>40 \mathrm{~mm}$ in men.

An independent, certified third-party data monitor controlled the integrity of the data at each study site. The study protocol was approved by the Medical Ethics Committee of the Hospital District of Southwest Finland and the ethics committee of the National Institute for Health and Welfare (Finland). Because of the retrospective, observational nature of the study, informed consent was not required. The study conformed to the Declaration of Helsinki.

\section{Statistical Analysis}

Statistical analyses were conducted with SPSS version 25.0 statistical software (IBM Corp, Albany, NY) and R statistics software version 4.0.0 (R Foundation for Statistical Computing, Vienna, Austria). Continuous variables were reported as mean \pm standard deviation if normally distributed, and as median (25th-75th percentiles) if they were skewed. The data were tested for normal distribution using Kolmogorov-Smirnov and Shapiro-Wilk tests. Categorical variables were described as counts and percentages. Cox proportional hazards model, unpaired $t$ test, and MannWhitney test were used for univariable analysis. The Cox regression proportional hazards assumption was assessed using graphical methods.

Least absolute shrinkage and selection operator regression analyses. K-nearest neighbors imputation using all baseline data as factors was applied to missing data in the multivariable models (R package simputation, version 0.2 .4$),{ }^{18}$ apart from the variables presenting $\geq 15 \%$ of missing data in one or more of the analysis subgroups, in which case an additional factor level of "not applicable" was introduced after the conversion of continuous variables to binary. The continuous variables were scaled and centered before regression analyses. Least absolute shrinkage and selection operator (Lasso)penalized Cox regression was used to trace the association of baseline factors and AF after hospital discharge ( $\mathrm{R}$ package glmnet, version 3.0-2). ${ }^{19,20}$ The Lasso model that resulted in minimal prediction error in 10-fold crossvalidation was selected. From the Lasso model with the least prediction error, we selected interactions with penalized $\beta$ coefficients $\geq 0.1$ or $\leq-0.1$ to retain the most relevant parameters. Cardioversion during the index hospitalization as a variable was excluded from the multivariable analyses because of its association with AF during the index hospitalization. The European System for Cardiac Operative Risk Evaluation (EuroSCORE) II was excluded from the Lasso analyses because of its association with multiple baseline characteristics. Center number was included in all multivariable analyses to address the potential reporting bias caused by the multicenter approach.

Multilevel Cox models. Multivariable multilevel Cox regression analyses were used to analyze the association of AF during the index hospitalization and adverse outcomes ( $\mathrm{R}$ package coxme, version 2.2-16). ${ }^{21}$ We included the different research sites as separate levels by adding the center number as a random effect in the models. Because of the differences in the years of entry into the study, a 3-level random intercept model including the year of entry within research site was exploited. In addition, the Cox regression multivariable mixed effects models were adjusted for EuroSCORE II, age during the operation, the direct continuation of oral anticoagulation after 3 months postoperatively (combined and bioprosthetic cohorts), and prosthesis type (combination cohort) as fixed effects. Patients who died within 30 days after the surgery were excluded from the mortality analyses to minimize the potential bias caused by the comorbidities related to perioperative mortality.

Cause-specific competing risk hazard models accounting for death were used for stroke and late AF analysis. Cumulative incidence function, person-years and linearized rate analysis were used to estimate the cumulative $\mathrm{AF}$ rate after hospital discharge and stroke rate. Multiple testing correction was not applied because of the explorative nature of the study.

\section{RESULTS}

A total of 1073 patients underwent isolated SAVR at the 4 participating hospitals. The follow-up data for mortality were complete for $1073(100.0 \%)$ patients and for other end points for $1004(93.6 \%)$ patients. Of the patients who underwent mechanical SAVR, 20/296 (6.8\%) had permanent AF and 23/296 (7.8\%) had a history of paroxysmal/persistent AF before the operation. Similarly, of the patients who underwent bioprosthetic SAVR, 84/708 (11.9\%) had permanent $\mathrm{AF}$ and 95/708 (13.4\%) had a history of paroxysmal/persistent $\mathrm{AF}$ before the operation. The exclusion of patients with permanent or paroxysmal AF before the operation resulted in a total of 529 patients in the bioprosthetic cohort and 253 patients in the mechanical cohort. The mortality analyses of the mechanical cohort included overall 301 patients. The baseline characteristics and operative data of patients with and without AF after hospital discharge are detailed in Table 1.

\section{Incidence of In-Hospital NOAF and AF After Hospital Discharge}

The median follow-up time was 5.4 (interquartile range, 3.4-8.2) years. A total of $333(42.6 \%)$ patients experienced in-hospital NOAF and $250(32.0 \%)$ patients $\mathrm{AF}$ after discharge. In the mechanical cohort, a total of $64(25.3 \%)$ patients had in-hospital NOAF and $74(29.2 \%)$ patients AF after discharge (5.05/100 person-years). Similarly, of the patients in the bioprosthetic cohort $269(50.9 \%)$ patients experienced in-hospital NOAF and $176(33.3 \%)$ patients AF later after hospital discharge (incidence rate 8.82/100 person-years). Cumulative incidence estimates of cumulative AF after hospital discharge at 30 days, 3 months, and 1 and 5 years were $12.3 \%, 15.9 \%, 17.5 \%$, and $22.7 \%$ in the mechanical cohort, and $16.8 \%, 21.4 \%, 24.6 \%$, and $30.6 \%$ in the bioprosthetic cohort, respectively. In the mechanical cohort, AF after hospital discharge occurred in $31(48.4 \%)$ patients with in-hospital NOAF (9.55/100 person-years) and $43(22.8 \%)$ patients without in-hospital NOAF (3.77/100 person-years). Similarly, of the patients in the bioprosthetic cohort, AF after hospital discharge occurred in 137 (50.6\%) patients with in-hospital $\operatorname{NOAF}(17.6 / 100$ person-years) and $39(15.2 \%)$ patients without in-hospital NOAF (3.23/100 person-years).

In the patients with previous open-heart cardiac surgery, NOAF during the index hospitalization occurred in 17 $(39.5 \%)$ patients (mechanical cohort: 3 [20.0\%]; bioprosthetic cohort: 14 [50.0\%]), and $\mathrm{AF}$ after hospital discharge in $14(32.6 \%)$ patients (mechanical cohort: 5 [33.3\%]; bioprosthetic cohort: 9 [32.1\%]). 
TABLE 1. Baseline characteristics and operative data of patients who underwent isolated mechanical or bioprosthetic aortic valve replacement with and without $\mathrm{AF}$ after hospital discharge

\begin{tabular}{|c|c|c|c|c|}
\hline & AF after discharge $(n=250)$ & No $A F(n=532)$ & HR $(95 \%$ CI $)$ & $P$ value \\
\hline Age & $73.0(66.0-78.0)$ & $70.0(62.0-77.0)$ & $1.03(1.02-1.04)$ & $<.001$ \\
\hline Female sex & $125(50.0)$ & $262(49.2)$ & $1.11(0.86-1.42)$ & .421 \\
\hline Diabetes & $30(12.0)$ & $91(17.1)$ & $0.81(0.55-1.19)$ & .284 \\
\hline Dyslipidemia & $135(54.4)$ & $259(48.7)$ & $1.30(1.01-1.68)$ & .038 \\
\hline Hypertension & $180(72.0)$ & $330(62.0)$ & $1.60(1.22-2.12)$ & .001 \\
\hline Peripheral artery disease & $12(4.8)$ & $19(3.6)$ & $1.46(0.82-2.61)$ & .204 \\
\hline Coronary artery disease & $57(22.8)$ & $102(19.2)$ & $1.34(1.00-1.80)$ & .052 \\
\hline Chronic lung disease & $43(17.3)$ & $67(12.6)$ & $1.40(1.01-1.95)$ & .044 \\
\hline Active smoking & $12(6.1)$ & $57(12.4)$ & $0.49(0.28-0.89)$ & .018 \\
\hline Active or ex-smoker & $54(28.4)$ & $164(37.2)$ & $0.72(0.52-0.98)$ & .039 \\
\hline Body mass index & $27.5(25.5-31.1)$ & $27.6(24.6-30.8)$ & $0.99(0.99-1.01)$ & .870 \\
\hline Active endocarditis & $8(3.2)$ & $23(4.3)$ & $0.69(0.34-1.40)$ & .304 \\
\hline Previous endocarditis & $5(2.0)$ & $15(2.8)$ & $0.64(0.26-1.56)$ & .325 \\
\hline Previous venous thromboembolism & $4(1.6)$ & $9(1.7)$ & $1.08(0.40-2.91)$ & .876 \\
\hline Previous stroke or TIA & $32(13.1)$ & $54(10.4)$ & $1.36(0.94-1.97)$ & .106 \\
\hline Previous myocardial infarction & $18(7.2)$ & $20(3.8)$ & $1.80(1.11-2.92)$ & .016 \\
\hline Previous percutaneous coronary intervention & $12(4.8)$ & $34(6.4)$ & $0.87(0.49-1.56)$ & .639 \\
\hline Previous cardiac surgery & $14(5.6)$ & $29(5.5)$ & $1.14(0.66-1.95)$ & .637 \\
\hline EuroSCORE II, \% & $1.6(1.0-2.5)$ & $1.4(0.9-2.1)$ & $1.02(1.00-1.05)$ & .092 \\
\hline NYHA class III or more & $136(54.4)$ & $226(42.5)$ & $1.51(1.18-1.94)$ & .001 \\
\hline Left ventricular ejection fraction, $\%$ & $60.0(51.0-69.0)$ & $62.0(54.0-70.0)$ & $0.99(0.98-1.01)$ & .271 \\
\hline Left atrium diameter, $\mathrm{mm}$ & $43.0(39.0-47.0)$ & $41.0(36.0-45.0)$ & $1.04(1.02-1.06)$ & .001 \\
\hline Aortic valve peak pressure gradient, $\mathrm{mm} \mathrm{Hg}$ & $81.0(68.5-99.5)$ & $80.0(66.0-99.0)$ & $1.00(0.99-1.01)$ & .952 \\
\hline $\begin{array}{l}\text { Aortic valve regurgitation } \\
\text { Aortic valve regurgitation degree* }\end{array}$ & $\begin{array}{l}147(61.0) \\
1.0(1.0-3.0)\end{array}$ & $\begin{array}{l}304(59.4) \\
1.0(1.0-3.0)\end{array}$ & $\begin{array}{l}1.03(0.79-1.33) \\
0.99(0.83-1.16)\end{array}$ & $\begin{array}{l}.854 \\
.812\end{array}$ \\
\hline $\begin{array}{l}\text { Mitral valve regurgitation } \\
\text { Mitral valve regurgitation degree } \dagger\end{array}$ & $\begin{array}{l}125(51.7) \\
1.0(1.0-2.0)\end{array}$ & $\begin{array}{l}284(44.1) \\
1.0(1.0-1.0)\end{array}$ & $\begin{array}{l}1.39(1.08-1.79) \\
1.55(1.19-2.00)\end{array}$ & $\begin{array}{l}.011 \\
.001\end{array}$ \\
\hline \multicolumn{5}{|l|}{ Pulmonary artery hypertension } \\
\hline $\begin{array}{l}\text { Moderate to severe (systolic } \geq 31 \mathrm{Mm} \mathrm{Hg} \text { ) } \\
\text { Severe (systolic } \geq 51 \mathrm{~mm} \mathrm{Hg} \text { ) }\end{array}$ & $\begin{array}{c}38(21.7) \\
7(4.0)\end{array}$ & $\begin{array}{l}58(14.1) \\
11(2.7)\end{array}$ & $\begin{array}{l}1.28(0.89-1.84) \\
1.02(0.48-2.19)\end{array}$ & $\begin{array}{l}.184 \\
.953\end{array}$ \\
\hline Urgent, emergency, or salvage procedure & $17(6.8)$ & $36(6.8)$ & $1.15(0.70-1.88)$ & .588 \\
\hline Pulse & $69.5(61.0-78.0)$ & $68.0(61.0-77.0)$ & $1.00(0.99-1.01)$ & .739 \\
\hline Valve prosthesis size, $\mathrm{mm}$ & $23.0(21.0-25.0)$ & $23.0(21.0-25.0)$ & $1.03(0.97-1.11)$ & .345 \\
\hline \multicolumn{4}{|l|}{ Preoperative laboratory values } & .025 \\
\hline $\begin{array}{l}\text { Postoperative laboratory values } \\
\text { EGFR, } \mathrm{mL} / \mathrm{min} / 1.73 \mathrm{~m}^{2} \text { minimum } \\
\text { CK-MB, } \mu \mathrm{g} / \mathrm{L} \text { maximum }\end{array}$ & $\begin{array}{l}75.3(55.5-94.0) \\
29.5(21.0-41.4)\end{array}$ & $\begin{array}{l}78.0(61.0-99.0) \\
26.5(19.9-38.9)\end{array}$ & $\begin{array}{l}0.99(0.99-1.00) \\
1.00(1.00-1.00)\end{array}$ & $\begin{array}{l}.004 \\
.599\end{array}$ \\
\hline NOAF during index hospitalization & $168(67.2)$ & $167(31.6)$ & $3.68(2.82-4.81)$ & $<.001$ \\
\hline Cardioversion during hospitalization & $71(28.4)$ & $59(11.2)$ & $2.57(1.95-3.39)$ & $<.001$ \\
\hline Reoperation due to bleeding & $21(8.4)$ & $41(7.7)$ & $1.18(0.75-1.84)$ & .478 \\
\hline Delayed ventilation & $21(8.4)$ & $45(8.5)$ & $1.18(0.75-1.84)$ & .474 \\
\hline
\end{tabular}


TABLE 1. Continued

\begin{tabular}{|c|c|c|c|c|}
\hline & AF after discharge $(n=250)$ & No AF $(n=532)$ & HR $(95 \%$ CI $)$ & $P$ value \\
\hline Acute de novo dialysis & $2(0.8)$ & $7(1.3)$ & $0.82(0.21-3.33)$ & .790 \\
\hline In-hospital death & $1(0.4)$ & $11(2.1)$ & $1.36(0.19-9.73)$ & .759 \\
\hline Length of hospital stay & $9.0(7.0-11.0)$ & $8.0(7.0-10.0)$ & $0.99(0.97-1.01)$ & .182 \\
\hline
\end{tabular}

Continuous variables are reported as median with (interquartile range) or mean \pm standard deviation. Other data are reported as $\mathrm{n}(\%) . A F$, Atrial fibrillation; $H R$, hazard ratio; $C I$, confidence interval; TIA, transient ischemic attack; EuroSCORE, European System for Cardiac Operative Risk Evaluation; NYHA, New York Heart Association; $e$ GFR, estimated glomerular filtration rate; $C K-M B$, creatinine kinase-MB; $N O A F$, new-onset atrial fibrillation. *Within the patients with aortic valve regurgitation. †Within the patients with mitral valve regurgitation.

\section{Predictors of AF After Hospital Discharge}

The stable predictors of AF after hospital discharge with penalized $\beta$ coefficients $\geq 0.1$ or $\leq-0.1$ in Lasso regression analysis in the mechanical and bioprosthetic patient cohorts combined and separately are presented in Table 2 . In combined as well as in the mechanical and the bioprosthetic cohorts, the multivariable model identified mitral valve regurgitation degree III or more and NOAF during the index hospitalization as independent predictors of $\mathrm{AF}$ after hospital discharge. In the combined and bioprosthetic cohorts, active smoking was identified as an independent protective factor and left atrium dilatation as an independent predisposing factor for $\mathrm{AF}$ after hospital discharge, although the effects seemed to originate from both of the cohorts (Tables E1 and E2). Moderate to severe postoperative renal impairment also was associated with higher late $\mathrm{AF}$ rate in the combined cohort and in the bioprosthetic cohort.

TABLE 2. The predictors of atrial fibrillation after hospital discharge

\begin{tabular}{|c|c|c|c|}
\hline & $\begin{array}{c}\begin{array}{c}\text { Mechanical } \\
\text { AVR }\end{array} \\
\beta^{*}\end{array}$ & $\begin{array}{c}\begin{array}{c}\text { Bioprosthetic } \\
\text { AVR }\end{array} \\
\beta^{*}\end{array}$ & $\begin{array}{c}\begin{array}{c}\text { Both } \\
\text { cohorts }\end{array} \\
\beta^{*}\end{array}$ \\
\hline Age & NS & NS & 0.112 \\
\hline Hypertension & NS & NS & 0.115 \\
\hline Peripheral artery disease & NS & NS & 0.245 \\
\hline Chronic lung disease & NS & NS & 0.153 \\
\hline Active smoking & NS & -0.157 & -0.369 \\
\hline Previous stroke or TIA & NS & NS & 0.168 \\
\hline $\begin{array}{l}\text { Previous myocardial } \\
\text { infarction }\end{array}$ & 0.533 & NS & 0.290 \\
\hline Left atrium dilatation & NS & 0.208 & 0.217 \\
\hline $\begin{array}{l}\text { Mitral valve regurgitation } \\
\text { degree III or more }\end{array}$ & 0.234 & 0.490 & 0.776 \\
\hline Valve prosthesis size, $\mathrm{mm}$ & 0.151 & NS & NS \\
\hline $\begin{array}{l}\text { Postoperative eGFR } \\
\text { minimum }<60 \mathrm{~mL} / \mathrm{min} / \\
1.73 \mathrm{~m}^{2}\end{array}$ & NS & 0.182 & 0.241 \\
\hline $\begin{array}{l}\text { NOAF during index } \\
\text { hospitalization }\end{array}$ & 0.599 & 1.115 & 1.112 \\
\hline Length of hospital stay & NS & NS & -0.106 \\
\hline
\end{tabular}

$\overline{A V R}$, Aortic valve replacement; $\beta$, penalized $\beta$-coefficient; $N S$, not significant; TIA, transient ischemic attack; $e G F R$, estimated glomerular filtration rate; NOAF, newonset atrial fibrillation. *All main effects and interactions with a $\beta \geq 0.1$ or $\leq-0.1$ selected in Lasso regression analysis.
Furthermore, previous myocardial infarction was identified in the mechanical and in the combined cohort and larger valve prosthesis size was identified in the mechanical cohort as independent predictors of late AF. The predictors only identified in the combination cohort included advanced age, hypertension, peripheral artery disease, chronic lung disease, previous stroke or TIA, and shorter hospital stay. In a more detailed analysis of the mechanical cohort, patients with larger valve prosthesis size were significantly younger ( $<25 \mathrm{~mm}$ : 60.0 [54.0-64.0] years vs $\geq 25 \mathrm{~mm}$ : 56.0 [44.8-63.0] years; $P=.005)$, had lower left ventricular ejection fraction $(<25 \mathrm{~mm}: 64.0[57.0-70.0] \%$ vs $\geq 25 \mathrm{~mm}$ : $57.0[50.0-65.8] \% ; P<.001)$, and had more often aortic valve regurgitation $(78.6 \%$ vs $59.2 \% ; P=.001)$.

\section{NOAF During Index Hospitalization and Adverse Outcomes}

Overall $52(17.3 \%)$ patients in the mechanical cohort and $205(38.3 \%)$ patients in the bioprosthetic cohort died during the study period. Median follow-up time for death was 10.4 (6.7-12.5 years) years in the mechanical cohort and 8.4 (6.510.4 years) years in the bioprosthetic cohort. Patients who died within 30 days after the surgery (22 patients; $2.6 \%$ ) were excluded from the mortality analyses to minimize the potential bias caused by the comorbidities related to perioperative mortality. Patients with a NOAF episode during the index hospitalization had significantly higher risk of death during the follow-up in the mechanical cohort (hazard ratio [HR], $2.29 ; 95 \%$ confidence interval $[\mathrm{CI}], 1.26-4.15 ; P=.006)$ and the bioprosthetic patient cohort (HR, 1.86; 95\% CI, 1.38-2.51; $P<.001$; Figure 1). After adjustment for EuroSCORE II, age during the operation, the direct continuation of oral anticoagulation after 3 months postoperatively (combined and bioprosthetic cohorts), and prosthesis type (combined cohort), in addition to center number and the year of the index operation (random effects), the risk for higher mortality remained in the combined cohort (HR, 1.65; 95\% CI, 1.23-2.21; $P<.001$ ) and in each cohort separately (mechanical cohort: HR, 2.05; 95\% CI, 1.10-3.82; $P=.025$; bioprosthetic cohort: HR, $1.63 ; 95 \%$ CI, 1.17-2.28'; $P=.004)$. There was an evident difference in the EuroSCORE II values of the patients who died after in-hospital NOAF when patients in the mechanical and bioprosthetic cohorts were compared (median EuroSCORE II $1.3 \%$ vs $1.9 \% ; P=.010$ ). 


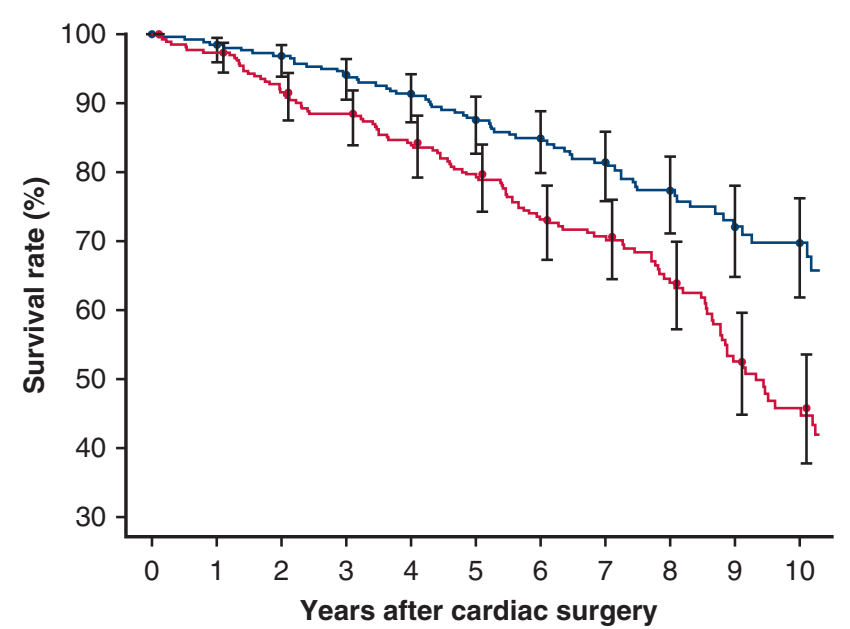

Patients at risk

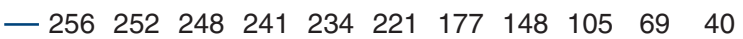

$\begin{array}{lllllllllll}-261 & 254 & 239 & 231 & 220 & 206 & 166 & 128 & 96 & 63 & 41\end{array}$

- BIO: NOAF during index hospitalization -

- BIO: NOAF during index hospitalization +

A

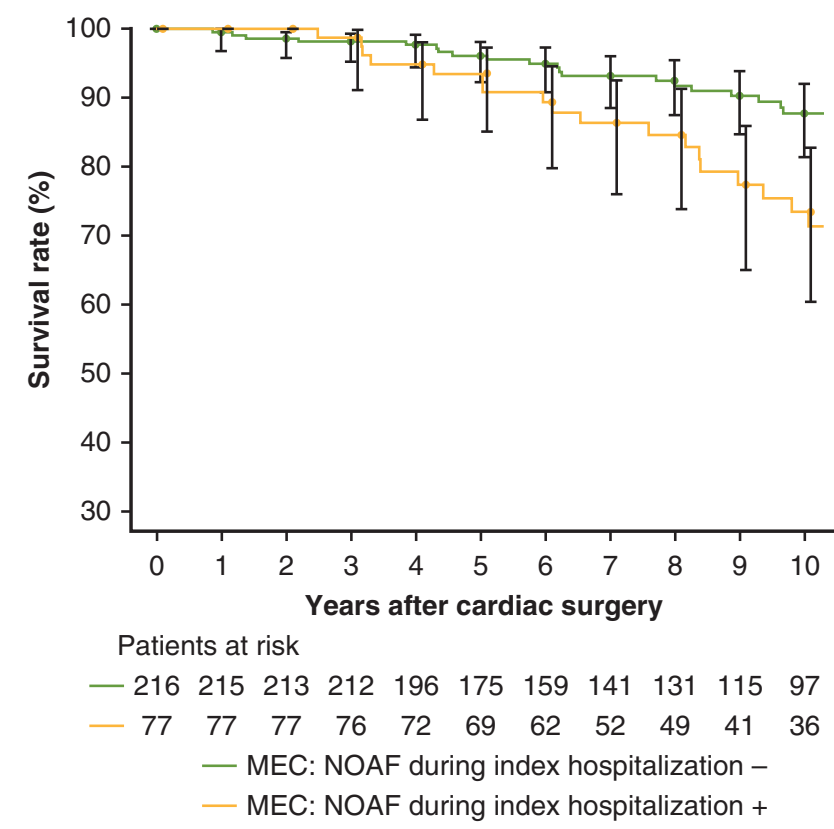

B

FIGURE 1. Survival after isolated surgical aortic valve replacement (SAVR) in patients undergoing (A) bioprosthetic $(B I O)$ and $(\mathrm{B})$ mechanical $(M E C H)$ valve procedure with no previous atrial fibrillation episodes stratified according to the appearance of new-onset atrial fibrillation (NOAF) during the index hospitalization. Patients alive 30 days after the surgery are included.

The death certificate diagnoses of death after 30 days postoperatively were available in $19(95.0 \%)$ patients in the mechanical cohort with a NOAF episode during the index hospitalization and $109(88.6 \%)$ patients in the bioprosthetic cohort. Stroke accounted for $2(10.5 \%)$ and 6

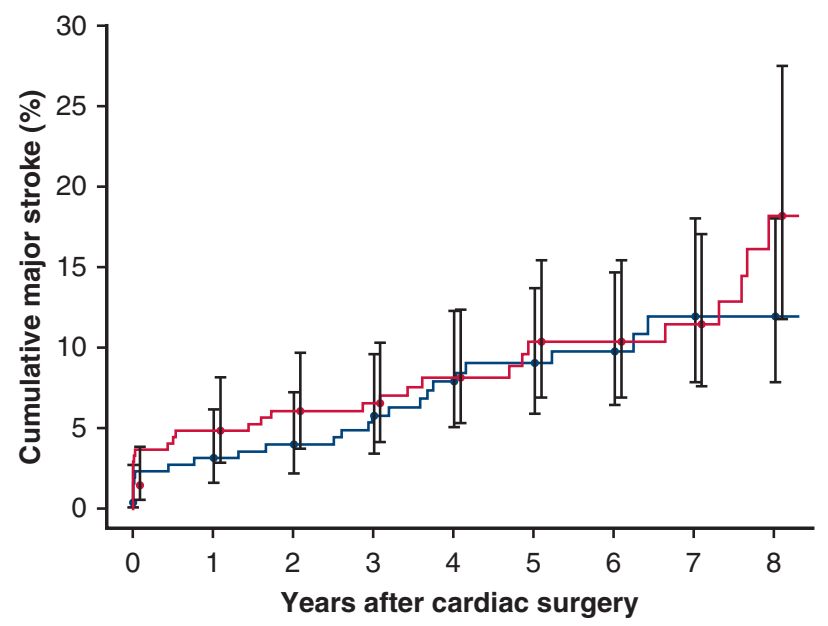

Patients at risk

$\begin{array}{lllllllll}-259 & 239 & 229 & 198 & 165 & 135 & 91 & 61 & 39 \\ -274 & 241 & 218 & 193 & 150 & 117 & 91 & 71 & 38\end{array}$

- BIO: NOAF during index hospitalization -

- BIO: NOAF during index hospitalization +

A

$(5.5 \%)$ of the deaths after in-hospital NOAF in the mechanical and bioprosthetic cohorts, respectively. In the patients without in-hospital NOAF during the index hospital stay, stroke accounted for 0 and $7(13.0 \%)$ of the deaths in the mechanical and bioprosthetic cohorts, respectively. After

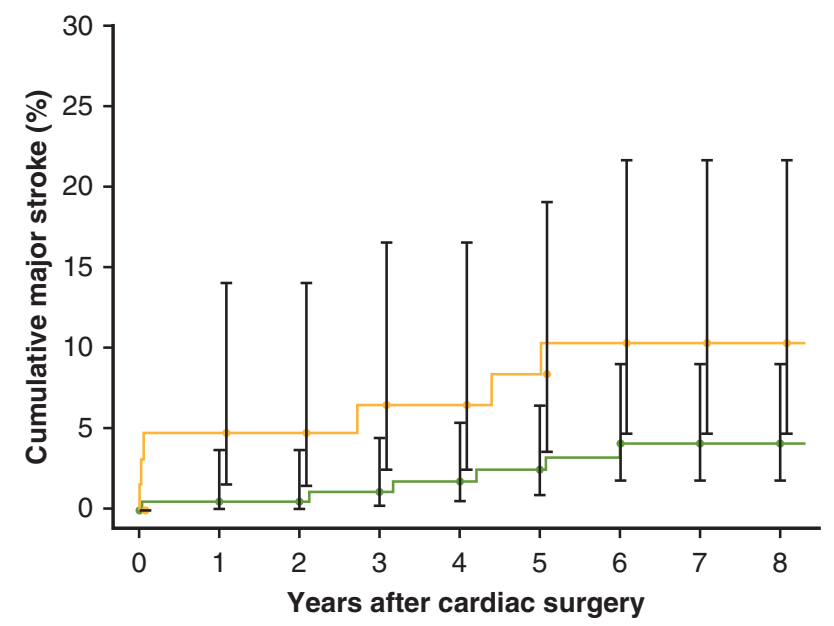

Patients at risk

$\begin{array}{lllllllll}-189 & 176 & 166 & 154 & 143 & 126 & 109 & 96 & 84\end{array}$

$\begin{array}{lllllllll}-64 & 57 & 55 & 52 & 50 & 47 & 43 & 39 & 36\end{array}$

- MEC: NOAF during index hospitalization -

- MEC: NOAF during index hospitalization +

B

FIGURE 2. Cumulative incidence of major stroke after isolated surgical aortic valve replacement (SAVR) in patients undergoing (A) bioprosthetic (BIO) and $(\mathrm{B})$ mechanical $(M E C H)$ valve procedure with no previous atrial fibrillation episodes stratified according to the appearance of new-onset atrial fibrillation $(N O A F)$ during the index hospitalization. 
in-hospital NOAF, the most common causes of death were coronary artery disease, cancer-related death, different types of dementia, and different types of heart failure typically related to either coronary artery disease or aortic stenosis, referring to preoperative aortic stenosis. Pneumonia was the most common immediate cause of death.

Cumulative incidence estimates of the cumulative major stroke rates at 30 days, 3 months, and 1 and 5 years were $1.6 \%, 1.6 \%, 1.6 \%$, and $3.9 \%$ in the mechanical cohort, and $3.0 \%, 3.0 \%, 3.9 \%$, and $8.8 \%$ in the bioprosthetic cohort, respectively. NOAF paroxysms during the index hospitalization were not significantly associated with postoperative major stroke either in the combined cohort (HR, 1.60 ; 95\% CI, 0.99-2.59; $P=.055$ ) or in the cohorts separately (mechanical cohort: $\mathrm{HR}, 2.11$; 95\% CI, 0.73-6.08; $P=.168$; bioprosthetic cohort: HR, 1.21; 95\% CI, 0.702.08; $P=.495$ ). However, a trend (nonsignificant) toward higher rates of major stroke occurrence during the first weeks after the surgery was observable in the mechanical cohort, as indicated in the competing risk analysis (Figure 2). When the combination of both end points was evaluated, NOAF paroxysms during the index hospital stay were significantly associated with a higher risk of stroke or death in the combination cohort (HR, 2.40; 95\% CI, 1.80-3.20; $P<.001)$ and in both of the cohorts separately (mechanical cohort: HR, 1.98; 95\% CI, 1.07-3.64; $P=.029$; bioprosthetic cohort: HR, 1.88 ; 95\% CI, 1.34$2.62 ; P<.001)$ after the exclusion of deaths within 30 days. After adjustment for EuroSCORE II, age during the operation, the direct continuation of oral anticoagulation after 3 months postoperatively (combined and bioprosthetic cohorts), and prosthesis type (combined cohort), in addition to center number and the year of the index operation (random effects), the higher risk remained significant in the combination cohort and in the bioprosthetic cohort (both cohorts: HR, 1.57; 95\% CI, 1.142.17; $P=.006$; bioprosthetic cohort: HR, $1.57 ; 95 \% \mathrm{CI}$, $1.08-2.28 ; P=.018$ ), but it did not reach statistical significance in the mechanical cohort (HR, 1.82; 95\% CI, 0.95$3.47 ; P=.072$ ). After similar adjustment, no significant difference in the risk of stroke or death was observed when NOAF patients with later AF recurrence were compared with patients with AF after hospital discharge only (combined cohort: HR, 1.26; 95\% CI, 0.72-2.22; $P=.420$; mechanical cohort: HR, 0.72; 95\% CI, 0.21-2.47; $P=.590$; bioprosthetic cohort: HR, 1.52; 95\% CI, 0.77-3.00; $P=.230$ ). The effect of NOAF on late AF is illustrated in Figures 3 and 4.

The median $\mathrm{CHA}_{2} \mathrm{DS}_{2}$-VASc scores were 1.0 (1.0-2.0) and $4.0(3.0-5.0)$ in the mechanical and bioprosthetic cohorts, respectively. The median score for NOAF patients was 4.0 (3.0-5.0) and patients with late AF occurring after hospital discharge with or without NOAF during the postoperative period had a preoperative score of 4.0 (2.0-5.0).
When NOAF patients with and without major stroke during the follow-up were compared, a significant difference in $\mathrm{CHA}_{2} \mathrm{DS}_{2}$-VASc scores was detected (median $\mathrm{CHA}_{2} \mathrm{DS}_{2}-$ VASc score 5.0 vs $4.0 ; P=.002$ ). Patients with NOAF presented higher $\mathrm{CHA}_{2} \mathrm{DS}_{2}$-VASc scores (mechanical cohort: median, 2.0 vs, $1.0 ; P=.001$; bioprosthetic cohort: 4.0 vs $4.0 ; P=.001)$. However, the association between NOAF and death after 30 days remained significant also after adjustment for $\mathrm{CHA}_{2} \mathrm{DS}_{2}$-VASc score, the direct continuation of oral anticoagulation after 3 months postoperatively (combined and bioprosthetic cohorts), and prosthesis type (combined cohort), in addition to center number and the year of the index operation (random effects) in the combined and bioprosthetic cohorts (combined cohort: HR, 1.62; 95\% CI, 1.21-2.17; $P=.001$; bioprosthetic cohort: HR, 1.54; 95\% CI, 1.11-2.14; $P=.011$ ) although it did not reach statistical significance in the mechanical cohort (HR, 1.77; 95\% CI, 0.93-3.36; $P=.083$ ). The results were similar when the association of NOAF and the combination end point of death after 30 days or stroke after similar adjustment for $\mathrm{CHA}_{2} \mathrm{DS}_{2}$-VASc score was evaluated (combined cohort: HR, 1.52; 95\% CI, 1.10-2.09; $P=.010$; mechanical cohort: HR, 1.46; 95\% CI, 0.743-2.88; $P=.270$; bioprosthetic cohort: HR, 1.50; 95\% CI, 1.03-2.17; $P=.033)$. Overall $120(96.0 \%)$ of the NOAF patients'

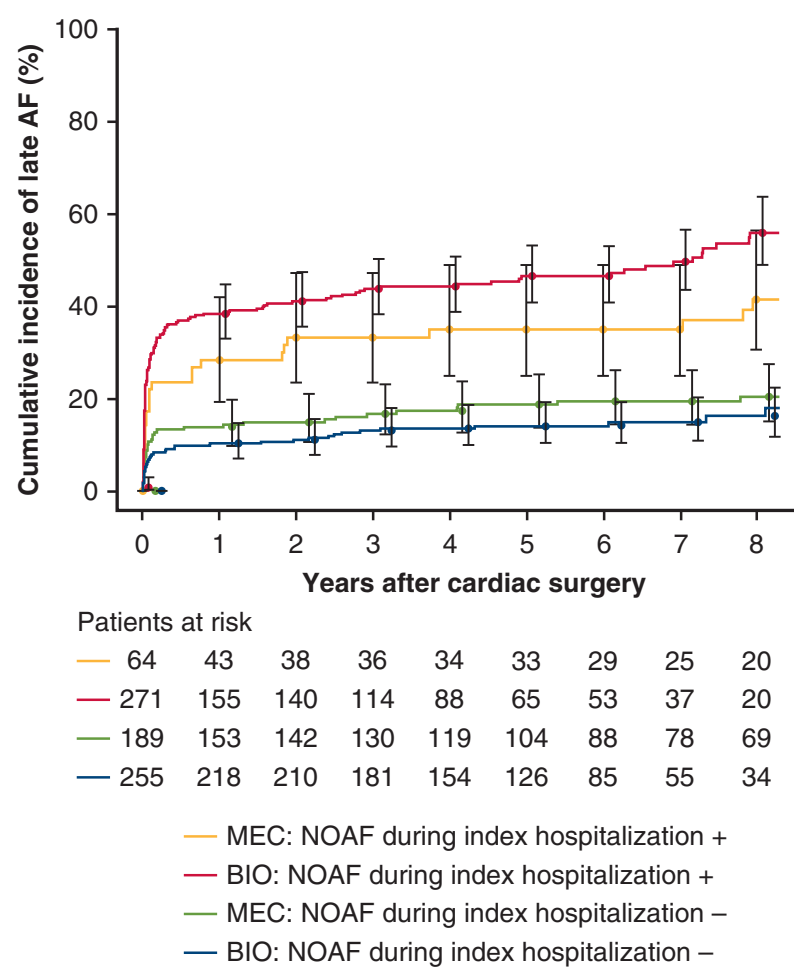

FIGURE 3. Cumulative incidence of late atrial fibrillation $(A F)$ after hospital discharge in patients with and without new-onset $\mathrm{AF}(N O A F)$ during the index hospitalization undergoing isolated aortic valve replacement with a bioprosthesis $(B I O)$ or a mechanical prosthesis $(M E C)$. 


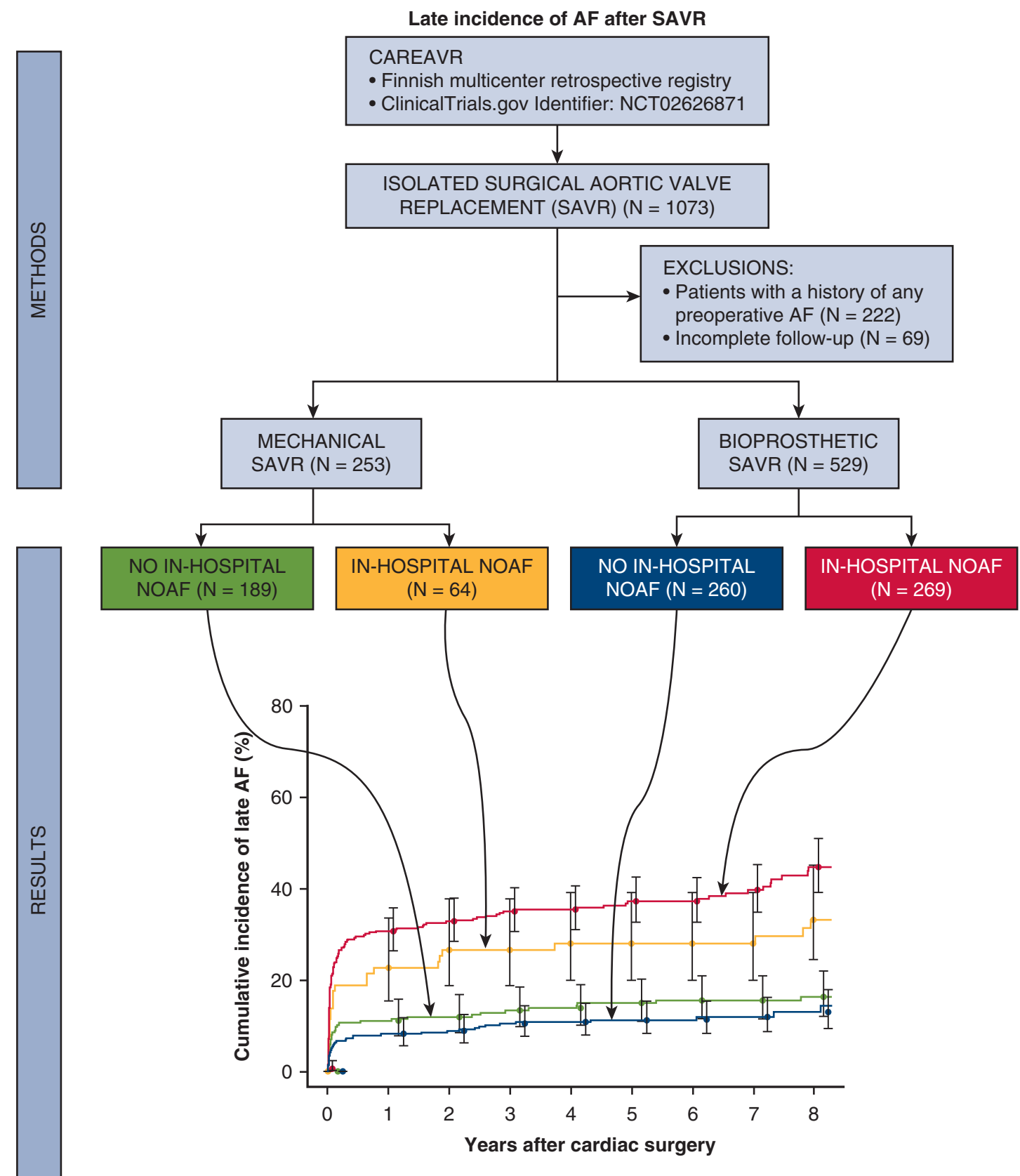

CLINICAL IMPLICATIONS:

Patients experiencing NOAF during hospital stay after SAVR are prone to the recurrence of AF later in life. Patients with NOAF and risk factors for stroke might be considered candidates for permanent OAC.

FIGURE 4. Late incidence of atrial fibrillation $(A F)$ after surgical aortic valve replacement (SAVR). Patients included in the study had no history of AF prior to SAVR. In = mechanical and bioprosthetic patient cohorts new-onset atrial fibrillation (NOAF) during the index hospital stay after SAVR increased the risk of late AF multifold. Patients with NOAF and risk factors for stroke might be considered candidates for permanent oral anticoagulation (OAC). CAREAVR, Consortium of Studies in the Field of Atrial Fibrillation, Stroke, and Bleeding in Patients Undergoing Aortic Valve Replacement.

deaths or strokes occurred in patients with high $\mathrm{CHA}_{2} \mathrm{DS}_{2}-$ VASc score (2 or more) and $51(40.8 \%)$ in patients with very high score (5 or more). The occurrence of the combination end point after in-hospital NOAF increased steadily with the increasing $\mathrm{CHA}_{2} \mathrm{DS}_{2}$-VASc score.

\section{DISCUSSION}

\section{Main Findings}

In-hospital NOAF appeared to be a strong biomarker of later AF and all-cause mortality after mechanical and bioprosthetic SAVR. 


\section{The Occurrence of AF After Hospital Discharge}

The present study showed that AF after hospital discharge occurred in half of the patients with in-hospital NOAF in the combined cohort as well as in the bioprosthetic and mechanical cohorts during long-term and accurate follow-up of 5 years. Furthermore, of the patients with late $\mathrm{AF}$ at 5-year follow-up, almost a half in the mechanical patient group and three-quarters in the bioprosthetic patient group had a NOAF episode also during the index hospitalization. In all of the patient groups, half of the AF paroxysms after hospital discharge appear within the first month (Figure 3). The actual AF occurrence after discharge is likely to be even higher, because only clinically detected AF events were included in this study.

The incidence of NOAF during the index hospitalization as well as AF after hospital discharge were notably high especially considering that none of the patients had a history of any kind of $\mathrm{AF}$ before the operation. The incidence of late AF during the first months after discharge was approximately similar after mechanical and bioprosthetic isolated SAVR. During the longer follow-up, patients who underwent bioprosthetic SAVR were more susceptible to developing AF. This could be explained because of the older age as well as higher prevalence of comorbidities such as hypertension, diabetes, and coronary artery disease. ${ }^{22-24}$ However, after dividing patients into those with and without NOAF during the index hospital stay, no significant difference between the bioprosthetic and mechanical patient cohorts could be detected (Figure 3). It appears therefore that the surgical trauma of the heart and the physical stress related to the cardiac surgery identifies the patients most vulnerable to experience late $\mathrm{AF}$, by triggering a NOAF episode during the index hospitalization. In patients with mechanical and bioprosthetic isolated SAVR, if a NOAF episode does not occur during the index hospitalization, the occurrence of late $\mathrm{AF}$ after hospital discharge is similar regardless of the differences in the risk factors for AF between the 2 groups.

Individual susceptibility (eg, genetic factors), ${ }^{25}$ significantly influence the risk of developing AF after cardiac surgery. These factors can cause a complex array of pathophysiological changes in the atria, which enhances ectopy and conduction disturbances, increasing the likelihood to develop or maintain $\mathrm{AF}^{26}$ Valvular heart disease also is an independent risk factor for $\mathrm{AF}^{27}$; a registry of patients with $\mathrm{AF}$ across 9 European countries showed that any valvular heart disease coexisted in $63.5 \%$ of AF patients. ${ }^{28}$ Besides individual susceptibility and valvular heart disease, there might be other unknown factors contributing to AF, which could also play a role in the development of AF during the index hospitalization and after discharge. In light of the present results, the susceptible individuals can be identified by careful rhythm monitoring during the hospital stay. This identification might enable effective targeting of possible preventive measures for later $\mathrm{AF}$ and cerebrovascular events, such as long-term oral anticoagulation, reducing the overall amount of adverse effects and costs of these measures. Well selected patients with NOAF and risk factors for stroke would presumably benefit from permanent oral anticoagulation but the more specific subgroups still remain to be elucidated.

\section{NOAF and Mortality}

Patients with NOAF during the index hospital stay had higher mortality during long-term follow-up in the mechanical and the bioprosthetic patient cohorts. The relative risk increment was similar in both cohorts although patients entering bioprosthetic SAVR are at a higher risk for postoperative death according to the EuroSCORE II values. Thus, in-hospital NOAF identifies a group of patients with an increased risk of death in the long term. Compared with previous studies, the postoperative mortality in the present study was markedly higher. ${ }^{1,2,10,11}$ However, these data reflect real-world practice and all-comers design, and therefore, the patient populations in high predictable mortality are not excluded.

\section{Risk Factors for AF After Hospital Discharge}

Increasing age, hypertension, chronic lung disease, previous stroke or TIA, previous myocardial infarction, left atrium dilatation, mitral valve regurgitation degree III or more, postoperative estimated glomerular filtration rate (minimum $<60 \mathrm{~mL} / \mathrm{min} / 1.73 \mathrm{~m}^{2}$ ), and NOAF during index hospitalization were shown as independent predictors of AF after hospital discharge. The length of hospital stay was identified as an independent protective factor for AF after hospital discharge. Ageing, hypertension, chronic lung disease, previous myocardial infarction, left atrium dilatation, mitral valve regurgitation, and decreased kidney function are commonly recognized predictors of $\mathrm{AF}^{29}$ Moreover, increasing age has also been identified as an independent predictor of NOAF and AF after hospital discharge. ${ }^{7,22-}$ ${ }^{24,30,31}$ In the mechanical cohort, also valve prothesis size was shown as an independent predictor of AF after hospital discharge. The effect of larger valve prosthesis size refers most likely to the dilated aortic annulus and different types of valvular diseases. Because the patients with larger valve prosthesis size were significantly younger, these are most likely the patients with congenital bicuspid aortic valve because it is also known to be associated with larger aortic annulus size. ${ }^{32}$ The patients with larger valve prosthesis size also had more often aortic valve regurgitation, and although the data were not available in the present analysis; this might result in the enlargement of left ventricle enddiastolic volumes. In the combined cohort as well as in the biological patient cohort, patients with active smoking 
had less AF after hospital discharge. This finding is in line with previous studies, ${ }^{33-35}$ although smoking is in general a well known predictor of $\mathrm{AF}^{29}$ A possible explanation for this is that patients susceptible for developing AF might have had AF paroxysms triggered by smoking before the operation, which led to exclusion from the present study.

\section{Strengths and Limitations}

A validated, structured case report form was used at all study sites, ensuring the uniformity of reporting. Data on late mortality were obtained from Statistics Finland, which ensures the quality of survival data of the patients. In addition, as a quality control of the database, a professional third party monitored the data. The main limitation of this study is its retrospective nature. However, the data were collected from electronic patient records in which data on baseline, operation, and outcomes are reported in detail at each of the participating hospitals. To obtain reliable and accurate follow-up data, only patients from the hospitals' catchment areas were included in this study. Also, the patient populations were from regional catchment areas where AF episodes and cerebrovascular events are treated exclusively at the participating centers. Another important limitation is that the detection of AF after hospital discharge was not on the basis of continuous ECG recording (eg, Holter or implantable rhythm recorders) but on ECG recordings during the 3- and 12month follow-up visits and ECGs of symptomatic or otherwise detected AF episodes. Thus, the actual AF occurrence after the surgery is likely to be even higher, because some of the asymptomatic AF episodes were most likely missed. The authors recognize the lack of external validation when addressing the predictors of $\mathrm{AF}$ after hospital discharge. However, the analyses were first executed in the bioprosthetic cohort only, followed by separate analyses on the mechanical and combined cohorts, allowing the critical evaluation of the identified predictors. The additional factors possibly affecting the risk of $\mathrm{AF}$ and arising during the follow-up period were unavailable, and therefore, these factors potentially modifying the results could not be analyzed. The baseline differences between the 2 patient cohorts were inevitable. The authors underline that the aim of this study was to compare the effect of NOAF on late AF in selected patients undergoing mechanical or biological aortic valve replacement rather than comparing the 2 valve types with each other. The small size is another limitation of this analysis, and therefore, these findings should be viewed as hypothesis-generating.

\section{CONCLUSIONS}

In conclusion, in-hospital NOAF after SAVR increased the risk of late AF 3.7-fold. In-hospital NOAF also

\section{Late incidence and recurrence of new-onset atrial fibrillation after isolated surgical aortic valve replacement.}

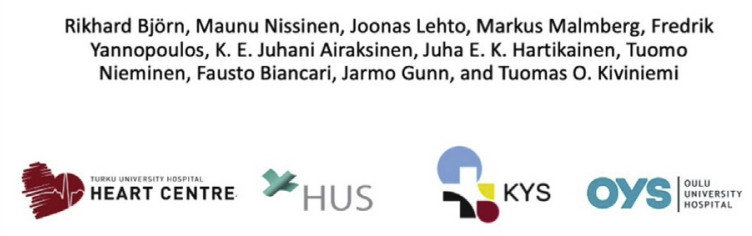

VIDEO 1. Lead author Rikhard Björn explains the key message of the article. Video available at: https://www.jtcvs.org/article/S0022-5223(21) 00587-0/fulltext.

increased long-term mortality 1.6- to 2-fold after mechanical and bioprosthetic SAVR (Video 1).

\section{Conflict of Interest Statement}

Maunu Nissinen received a research grant from Rättimäki Cardiovascular Society. Joonas Lehto received research grants from Orion Research Foundation, the Finnish Foundation for Cardiovascular Research, the Finnish Cultural Foundation, Turku University Foundation, and Emil Aaltonen Foundation. Markus Malmberg received research grants from the Clinical Research Fund (VTR) of Turku University Hospital, Turku, Finland; and the Finnish cultural foundation. K. E. Juhani Airaksinen received research grants from the Finnish Foundation for Cardiovascular Research, the Clinical Research Fund (VTR) of Turku University Hospital, Turku, Finland; and lecture fees from Bayer and Boehringer Ingelheim; and is a member in the advisory boards of Bayer, Astra Zeneca, and BristolMyers Squibb-Pfizer. Juha E. K. Hartikainen received research grants from the Finnish Foundation for Cardiovascular Research, Clinical Research Fund (VTR) of Kuopio University Hospital, Kuopio, Finland; and lecture fees from Cardiome AG and Astra Zeneca; and is a member of the advisory boards of Amgen, Pfizer, and Novo Nordisk. Tuomo Nieminen received research grants from AbbVie and Medtronic; research funds of Helsinki and Uusimaa Hospital District; and lecture fees from AstraZeneca, Boehringer Ingelheim, Finnish Consulting Group (FCG) Koulutus, GE Healthcare, Medtronic, Orion, and Sanofi. Jarmo Gunn received research grants from Turku University Research Foundation, Turku, Finland, the Clinical Research Fund (VTR) of Turku University Hospital, Turku, Finland, and an unrestricted grant from Vifor Pharma. Tuomas O. Kiviniemi received lecture fees from Bayer, Boehringer Ingelheim, MSD, Astra Zeneca, St Jude Medical, and Bristol- 
Myers-Squibb-Pfizer; research grants from the Finnish Medical Foundation, the Finnish Foundation for Cardiovascular Research, Clinical Research Fund (EVO) of Turku University Hospital, Turku, Finland, Finnish Cardiac Society, the Emil Aaltonen Foundation, the Maud Kuistila Foundation, and an unrestricted grant from Bristol-Myers Squibb-Pfizer; and is a member of the advisory board of Boehringer-Ingelheim and MSD. All other authors reported no conflicts of interest.

The Journal policy requires editors and reviewers to disclose conflicts of interest and to decline handling or reviewing manuscripts for which they may have a conflict of interest. The editors and reviewers of this article have no conflicts of interest.

The authors thank the study coordinator Tuija Vasankari, RN, for her input on data management.

\section{References}

1. Saxena A, Shi WY, Bappayya S, Dinh DT, Smith JA, Reid CM, et al. Postoperative atrial fibrillation after isolated aortic valve replacement: a cause for concern? Ann Thorac Surg. 2013;95:133-40.

2. Filardo G, Hamilton C, Hamman B, Hebeler RF, Adams J, Grayburn P. Newonset postoperative atrial fibrillation and long-term survival after aortic valve replacement surgery. Ann Thorac Surg. 2010;90:474-9.

3. Almassi GH, Schowalter T, Nicolosi AC, Aggarwal A, Moritz TE, Henderson WG, et al. Atrial fibrillation after cardiac surgery: a major morbid event? Ann Surg. 1997;226:501-13.

4. Banach M, Goch A, Misztal M, Rysz J, Jaszewski R, Goch JH. Predictors of paroxysmal atrial fibrillation in patients undergoing aortic valve replacement. $J$ Thorac Cardiovasc Surg. 2007;134:1569-76.

5. Helgadottir S, Sigurdsson MI, Ingvarsdottir IL, Arnar DO, Gudbjartsson T. Atrial fibrillation following cardiac surgery: risk analysis and long-term survival. J Cardiothorac Surg. 2012;7:87.

6. Kalra R, Patel N, Doshi R, Arora G, Arora P. Evaluation of the incidence of newonset atrial fibrillation after aortic valve replacement. JAMA Intern Med. 2019; 35294:1-9.

7. Tanawuttiwat T, O’Neill BP, Cohen MG, Chinthakanan O, Heldman AW, Martinez CA, et al. New-onset atrial fibrillation after aortic valve replacement: comparison of transfemoral, transapical, transaortic, and surgical approaches. $J$ Am Coll Cardiol. 2014;63:1510-9.

8. Mack MJ, Leon MB, Thourani VH, Makkar R, Kodali SK, Russo M, et al. Transcatheter aortic-valve replacement with a balloon-expandable valve in low-risk patients. N Engl J Med. 2019;380:1695-705.

9. Carter-Storch R, Dahl JS, Christensen NL, Pecini R, Søndergård EV, $\varnothing v$ rehus KA, et al. Postoperative atrial fibrillation after aortic valve replacement is a risk factor for long-term atrial fibrillation. Interact Cardiovasc Thorac Surg. 2019;29:378-85.

10. Kohno H, Ueda H, Matsuura K, Tamura Y, Watanabe M, Matsumiya G. Longterm consequences of atrial fibrillation after aortic valve replacement. Asian Cardiovasc Thorac Ann. 2017;25:179-91.

11. Swinkels BM, de Mol BA, Kelder JC, Vermeulen FE, Ten Berg JM. New-onset postoperative atrial fibrillation after aortic valve replacement: effect on long-term survival. J Thorac Cardiovasc Surg. 2017;154:492-8.

12. Mehta CK, McCarthy PM, Andrei A, Kruse J, Shi H, Churyla A, et al. De novo atrial fibrillation after mitral valve surgery. J Thorac Cardiovasc Surg. 2018;156: 1515-25.e11.

13. Airaksinen KEJ, Grönberg T, Nuotio I, Nikkinen M, Ylitalo A, Biancari F, et al. Thromboembolic complications after cardioversion of acute atrial fibrillation: the FinCV (Finnish CardioVersion) study. J Am Coll Cardiol. 2013;62:1187-92.

14. Nuotio I, Hartikainen JEK, Grönberg T, Biancari F, Airaksinen KEJ. Time to cardioversion for acute atrial fibrillation and thromboembolic complications. JAMA. 2014;312:647-9.
15. Lip GYH, Nieuwlaat R, Pisters R, Lane DA, Crijns HJGM, Andresen D, et al Refining clinical risk stratification for predicting stroke and thromboembolism in atrial fibrillation using a novel risk factor-based approach: the Euro Heart Survey on atrial fibrillation. Chest. 2010;137:263-72.

16. Hindricks G, Potpara T, Dagres N, Arbelo E, Bax JJ, Blomström-Lundqvist C, et al. 2020 ESC guidelines for the diagnosis and management of atrial fibrillation developed in collaboration with the European Association of Cardio-Thoracic Surgery (EACTS). Eur Heart J. 2021;42:373-498.

17. Adams HP, Bendixen BH, Kappelle LJ, Biller J, Love BB, Gordon DL, et al Classification of subtype of acute ischemic stroke. Stroke. 1993;23:35-41.

18. Van der Loo M. Simputation: Simple Imputation. R package version 0.2.4. Vienna, Austria: R Foundation for Statistical Computing; 2020.

19. Friedman J, Hastie T, Tibshirani R. Regularization paths for generalized linear models via coordinate descent. J Stat Softw. 2010;33:1-22.

20. Simon N, Friedman J, Hastie T, Tibshirani R. Regularization paths for Cox's proportional hazards model via coordinate descent. J Stat Softw. 2011;39:139-48.

21. Therneau TM. Coxme: Mixed Effects Cox Models. R package version 2.2-16 Vienna, Austria: R Foundation for Statistical Computing; 2020.

22. Pibarot P, Mathieu P, Voisine P, Girerd N, Magne J, Dagenais F. Postoperative atrial fibrillation predicts long-term survival after aortic-valve surgery but not after mitral-valve surgery: a retrospective study. BMJ Open. 2011;1:e000385.

23. Ahlsson A, Fengsrud E, Bodin L, Englund A. Postoperative atrial fibrillation in patients undergoing aortocoronary bypass surgery carries an eightfold risk of future atrial fibrillation and a doubled cardiovascular mortality. Eur J Cardiothorac Surg. 2010;37:1353-9.

24. LaPar DJ, Speir AM, Crosby IK, Fonner E, Brown M, Rich JB, et al. Postoperative atrial fibrillation significantly increases mortality, hospital readmission, and hospital costs. Ann Thorac Surg. 2014;98:527-33; discussion: 533.

25. Oyen N, Ranthe MF, Carstensen L, Boyd HA, Olesen MS, Olesen S, et al. Familial aggregation of lone atrial fibrillation in young persons. J Am Coll Cardiol. 2012;60:917-21.

26. Balouch MA, Kolek MJ, Darbar D. Improved understanding of the pathophysiology of atrial fibrillation through the lens of discrete pathological pathways. Glob Cardiol Sci Pract. 2014;2014:24-36.

27. Moretti M, Fabris E, Morosin M, Merlo M, Barbati G, Pinamonti B, et al. Prognostic significance of atrial fibrillation and severity of symptoms of heart failure in patients with low gradient aortic stenosis and preserved left ventricular ejection fraction. Am J Cardiol. 2014;114:1722-8.

28. Lip GYH, Laroche C, Dan G, Santini M, Kalarus Z, Rasmussen LH, et al. A prospective survey in European Society of Cardiology member countries of atrial fibrillation management: baseline results of EURObservational Research Programme Atrial Fibrillation (EORP-AF) Pilot General Registry. Europace. 2014;16:308-19.

29. Kirchhof P, Benussi S, Kotecha D, Ahlsson A, Atar D, Casadei B, et al. 2016 ESC guidelines for the management of atrial fibrillation developed in collaboration with EACTS. Eur Heart J. 2016;37:2893-962.

30. Rostagno C, La Meir M, Gelsomino S, Ghilli L, Rossi A, Carone E, et al. Atria fibrillation after cardiac surgery: incidence, risk factors, and economic burden. $J$ Cardiothorac Vasc Anesth. 2010;24:952-8.

31. Ismail MF, El-Mahrouk AF, Hamouda TH, Radwan H, Haneef A, Jamjoom AA. Factors influencing postoperative atrial fibrillation in patients undergoing onpump coronary artery bypass grafting, single center experience. J Cardiothorac Surg. 2017;12:40.

32. Philip F, Faza NN, Schoenhagen P, Desai MY, Tuzcu EM, Svensson LG, et al Aortic annulus and root characteristics in severe aortic stenosis due to bicuspid aortic valve and tricuspid aortic valves: implications for transcatheter aortic valve therapies. Catheter Cardiovasc Interv. 2015;86:E88-98.

33. Almassi GH, Wagner TH, Carr B, Hattler B, Collins JF, Quin JA, et al. Postoperative atrial fibrillation impacts on costs and one-year clinical outcomes: the veterans affairs randomized on/off bypass trial. Ann Thorac Surg. 2015;99:109-14.

34. Mariscalco G, Engström KG. Are current smokers paradoxically protected against atrial fibrillation after cardiac surgery? Nicotine Tob Res. 2009;11:58-63.

35. El-Chami MF, Kilgo P, Thourani V, Lattouf OM, Delurgio DB, Guyton RA, et al. New-onset atrial fibrillation predicts long-term mortality after coronary artery bypass graft. J Am Coll Cardiol. 2010;55:1370-6.

Key Words: surgical aortic valve replacement, new-onset atrial fibrillation 
TABLE E1. Baseline characteristics and operative data of patients who underwent isolated mechanical aortic valve replacement with and without AF after hospital discharge

\begin{tabular}{|c|c|c|c|c|}
\hline & AF after discharge $(n=74)$ & No AF $(n=179)$ & HR $(95 \%$ CI $)$ & $P$ value \\
\hline Age & $60.5(53.8-66.0)$ & $58.0(50.0-63.0)$ & $1.03(1.01-1.06)$ & .018 \\
\hline Female sex & $22(29.7)$ & $52(29.1)$ & $1.06(0.64-1.74)$ & .830 \\
\hline Diabetes & $5(6.8)$ & $19(10.6)$ & $0.74(0.30-1.83)$ & .510 \\
\hline Dyslipidemia & $33(44.6)$ & $65(36.3)$ & $1.41(0.89-2.23)$ & .143 \\
\hline Hypertension & $40(54.1)$ & $90(50.3)$ & $1.23(0.77-1.92)$ & .401 \\
\hline Peripheral artery disease & $1(1.4)$ & $1(0.6)$ & $2.39(0.33-17.29)$ & .388 \\
\hline Coronary artery disease & $10(13.5)$ & $19(10.6)$ & $1.35(0.69-2.64)$ & .374 \\
\hline Chronic lung disease & $7(9.5)$ & $11(6.1)$ & $1.61(0.74-3.51)$ & .230 \\
\hline Active smoking & $7(13.2)$ & $28(20.9)$ & $0.65(0.29-1.44)$ & .290 \\
\hline Active or ex-smoker & $19(35.8)$ & $66(49.3)$ & $0.69(0.39-1.21)$ & .191 \\
\hline Body mass index & $29.2 \pm 5.5$ & $27.8 \pm 4.8$ & $1.05(1.00-1.10)$ & .063 \\
\hline Active endocarditis & $4(5.4)$ & $14(7.8)$ & $0.67(0.24-1.83)$ & .429 \\
\hline Previous endocarditis & $2(2.7)$ & $13(7.3)$ & $0.39(0.10-1.60)$ & .193 \\
\hline Previous venous thromboembolism & $1(1.4)$ & $1(0.6)$ & $6.23(0.85-45.48)$ & .072 \\
\hline Previous stroke or TIA & $4(5.4)$ & $5(2.8)$ & $2.23(0.81-6.16)$ & .120 \\
\hline Previous myocardial infarction & $3(4.1)$ & $1(0.6)$ & $3.70(1.16-11.78)$ & .027 \\
\hline Previous percutaneous coronary intervention & $5(6.8)$ & $7(3.9)$ & $1.93(0.78-4.80)$ & .156 \\
\hline Previous cardiac surgery & $5(6.8)$ & $10(5.6)$ & $1.58(0.63-3.93)$ & .328 \\
\hline EuroSCORE II, \% & $0.9(0.7-1.4)$ & $0.9(0.7-1.3)$ & $1.00(0.93-1.07)$ & .907 \\
\hline NYHA class III or more & $28(37.8)$ & $68(38.0)$ & $1.00(0.62-1.59)$ & .982 \\
\hline Left ventricular ejection fraction, $\%$ & $58.0(47.0-67.0)$ & $63.0(54.0-70.0)$ & $1.00(0.97-1.00)$ & .101 \\
\hline Left atrium diameter, mm & $43.1 \pm 8.3$ & $40.7 \pm 7.8$ & $1.03(0.99-1.07)$ & .163 \\
\hline Aortic valve peak pressure gradient, $\mathrm{mm} \mathrm{Hg}$ & $81.0(63.0-100.0)$ & $88.0(70.0-103.0)$ & $0.99(0.98-1.00)$ & .090 \\
\hline Aortic valve regurgitation & $49(68.1)$ & $118(67.0)$ & $1.00(0.61-1.65)$ & .990 \\
\hline Aortic valve regurgitation degree* & $2.0(1.0-3.0)$ & $2.0(1.0-3.0)$ & $0.99(0.75-1.30)$ & .918 \\
\hline $\begin{array}{l}\text { Mitral valve regurgitation } \\
\text { Mitral valve regurgitation degree } \dagger\end{array}$ & $\begin{array}{l}28(39.4) \\
1.0(1.0-2.0)\end{array}$ & $\begin{array}{l}55(31.1) \\
1.0(1.0-1.0)\end{array}$ & $\begin{array}{l}1.39(0.86-2.24) \\
1.37(0.90-2.17)\end{array}$ & $\begin{array}{l}.174 \\
.174\end{array}$ \\
\hline \multicolumn{5}{|l|}{ Pulmonary artery hypertension } \\
\hline Moderate to severe; systolic $\geq 31 \mathrm{~mm} \mathrm{Hg}$ & $11(29.7)$ & $18(17.3)$ & $1.55(0.76-3.16)$ & .227 \\
\hline Severe; systolic $\geq 51 \mathrm{~mm} \mathrm{Hg}$ & $3(8.1)$ & $3(2.9)$ & $1.37(0.41-4.51)$ & .610 \\
\hline Urgent, emergency, or salvage procedure & $10(13.5)$ & $23(12.8)$ & $1.03(0.50-2.01)$ & .925 \\
\hline Pulse & $70.0(58.0-81.0)$ & $69.0(61.0-80.0)$ & $1.00(0.98-1.01)$ & .698 \\
\hline Valve prosthesis size, $\mathrm{mm}$ & $25.0(23.0-25.0)$ & $23.0(23.0-25.0)$ & $1.18(1.03-1.35)$ & .017 \\
\hline \multicolumn{5}{|l|}{ Preoperative laboratory values } \\
\hline EGFR & $83.1 \pm 17.8$ & $84.2 \pm 19.1$ & $1.00(0.99-1.01)$ & .823 \\
\hline \multicolumn{5}{|l|}{ Postoperative laboratory values } \\
\hline eGFR minimum & $92.0(78.0-98.9)$ & $95.7(80.0-107.5)$ & $0.99(0.98-1.00)$ & .043 \\
\hline CK-MB maximum & $30.7(23.5-45.9)$ & $30.8(23.7-41.7)$ & $1.00(0.99-1.01)$ & .667 \\
\hline NOAF during index hospitalization & $31(41.9)$ & $33(18.4)$ & $2.54(1.59-4.03)$ & $<.001$ \\
\hline Cardioversion during hospitalization & $15(20.3)$ & $20(11.2)$ & $1.70(0.97-3.00)$ & .066 \\
\hline Reoperation due to bleeding & $7(9.5)$ & $8(4.5)$ & $2.41(1.10-5.31)$ & .028 \\
\hline Delayed ventilation & $5(6.8)$ & $12(6.7)$ & $1.17(0.47-2.89)$ & .742 \\
\hline Acute de novo dialysis & $0(0.0)$ & $2(1.1)$ & $0.05(0.000-3806.08)$ & .600 \\
\hline
\end{tabular}


TABLE E1. Continued

\begin{tabular}{|c|c|c|c|c|}
\hline & AF after discharge $(n=74)$ & No $\mathbf{A F}(n=179)$ & HR $(95 \%$ CI $)$ & $P$ value \\
\hline In-hospital death & $0(0.0)$ & $6(3.4)$ & $0.05(0.00-9.75 \times 10 \mathrm{e} 6)$ & .049 \\
\hline Length of hospital stay & $9.0(7.0-11.0)$ & $8.0(7.0-10.0)$ & $0.99(0.97-1.11)$ & .578 \\
\hline
\end{tabular}


TABLE E2. Baseline characteristics and operative data of patients who underwent isolated bioprosthetic aortic valve replacement with and without AF after hospital discharge

\begin{tabular}{|c|c|c|c|c|}
\hline & AF after discharge $(n=176)$ & No AF $(n=353)$ & HR $(95 \%$ CI $)$ & $P$ value \\
\hline Age & $76.0(73.0-79.0)$ & $74.0(70.0-79.0)$ & $1.04(1.02-1.06)$ & .002 \\
\hline Female sex & $103(58.5)$ & $210(59.5)$ & $1.03(0.76-1.39)$ & .861 \\
\hline Diabetes & $25(14.3)$ & $72(20.4)$ & $0.77(0.51-1.18)$ & .231 \\
\hline Dyslipidemia & $102(58.6)$ & $194(55.0)$ & $1.16(0.86-1.57)$ & .335 \\
\hline Hypertension & $140(79.5)$ & $240(68.0)$ & $1.74(1.21-2.51)$ & .003 \\
\hline Peripheral artery disease & $11(6.3)$ & $18(5.1)$ & $1.23(0.67-2.26)$ & .516 \\
\hline Coronary artery disease & $47(26.7)$ & $83(23.5)$ & $1.25(0.89-1.74)$ & .193 \\
\hline Chronic lung disease & $36(20.6)$ & $56(15.9)$ & $1.24(0.86-1.79)$ & .254 \\
\hline Active smoking & $5(3.4)$ & $29(8.9)$ & $0.42(0.17-1.03)$ & .058 \\
\hline Active or ex-smoker & $35(25.5)$ & $98(31.9)$ & $0.79(0.54-1.15)$ & .217 \\
\hline Body mass index & $27.2(24.4-30.5)$ & $27.7(24.7-30.8)$ & $1.00(1.00-1.01)$ & .660 \\
\hline Active endocarditis & $4(2.3)$ & $9(2.6)$ & $0.91(0.34-2.46)$ & .854 \\
\hline Previous endocarditis & $3(1.7)$ & $2(0.6)$ & $1.88(0.59-5.94)$ & .285 \\
\hline Previous venous thromboembolism & $3(1.7)$ & $8(2.3)$ & $0.75(0.24-2.33)$ & .613 \\
\hline Previous stroke or TIA & $28(16.4)$ & $49(14.5)$ & $1.11(0.74-1.67)$ & .616 \\
\hline Previous myocardial infarction & $15(8.5)$ & $19(5.4)$ & $1.46(0.86-2.47)$ & .164 \\
\hline Previous percutaneous coronary intervention & $7(4.0)$ & $27(7.6)$ & $0.59(0.28-1.25)$ & .167 \\
\hline Previous cardiac surgery & $9(5.1)$ & $19(5.4)$ & $0.97(0.50-1.90)$ & .936 \\
\hline EuroSCORE II ( $\%)$ & $1.9(1.4-2.8)$ & $1.7(1.2-2.5)$ & $1.03(1.00-1.07)$ & .069 \\
\hline NYHA class III or more & $108(61.4)$ & $158(44.8)$ & $1.73(1.27-2.34)$ & $<.001$ \\
\hline Left ventricular ejection fraction, $\%$ & $61.0(54.0-69.3)$ & $61.0(53.0-70.0)$ & $1.00(0.99-1.01)$ & .978 \\
\hline Left atrium diameter, $\mathrm{mm}$ & $43.0(39.0-46.5)$ & $41.0(36.0-45.0)$ & $1.04(1.02-1.07)$ & .001 \\
\hline $\begin{array}{l}\text { Aortic valve peak pressure gradient, } \mathrm{mm} \mathrm{Hg} \\
\text { Aortic valve regurgitation }\end{array}$ & $\begin{array}{l}81.0(70.0-97.8) \\
98(58.0)\end{array}$ & $\begin{array}{l}78.0(65.0-95.0) \\
186(55.4)\end{array}$ & $\begin{array}{l}1.01(1.00-1.01) \\
1.10(0.81-1.49)\end{array}$ & $\begin{array}{l}.175 \\
.559\end{array}$ \\
\hline Aortic valve regurgitation degree* & $1.0(1.0-2.0)$ & $1.0(1.0-2.0)$ & $1.10(0.88-1.38)$ & .369 \\
\hline $\begin{array}{l}\text { Mitral valve regurgitation } \\
\text { Mitral valve regurgitation degree } \dagger\end{array}$ & $\begin{array}{l}97(56.7) \\
1.0(1.0-1.0)\end{array}$ & $\begin{array}{l}173(50.9) \\
1.0(1.0-1.0)\end{array}$ & $\begin{array}{l}1.27(0.94-1.71) \\
1.76(1.26-2.47)\end{array}$ & $\begin{array}{l}.128 \\
.001\end{array}$ \\
\hline \multicolumn{5}{|l|}{ Pulmonary artery hypertension } \\
\hline $\begin{array}{l}\text { Moderate to severe; systolic } \geq 31 \mathrm{~mm} \mathrm{Hg} \\
\text { Severe; systolic } \geq 55 \mathrm{~mm} \mathrm{Hg}\end{array}$ & $\begin{array}{c}27(19.6) \\
4(2.9)\end{array}$ & $\begin{array}{c}40(13.1) \\
8(2.6)\end{array}$ & $\begin{array}{l}1.23(0.81-1.83) \\
0.98(0.36-2.67)\end{array}$ & $\begin{array}{l}.335 \\
.963\end{array}$ \\
\hline Urgent, emergency, or salvage procedure & $7(4.0)$ & $13(3.7)$ & $1.05(0.49-2.24)$ & .900 \\
\hline Pulse & $69.0(62.0-76.0)$ & $68.0(60.8-77.0)$ & $1.01(0.99-1.02)$ & .288 \\
\hline Valve prosthesis size, $\mathrm{mm}$ & $23.0(21.0-23.0)$ & $23.0(21.0-23.0)$ & $1.01(0.92-1.09)$ & .912 \\
\hline \multicolumn{5}{|l|}{ Preoperative laboratory values } \\
\hline \multicolumn{5}{|l|}{ Postoperative laboratory values } \\
\hline EGFR minimum & $63.0(48.0-84.0)$ & $61.0(56.0-80.0)$ & $1.00(0.99-1.01)$ & .777 \\
\hline CK-MB maximum & $28.8(20.0-37.3)$ & $24.0(17.0-34.0)$ & $1.00(1.00-1.00)$ & .435 \\
\hline NOAF during index hospitalization & 137 (77.8) & $134(38.3)$ & $4.35(3.05-6.22)$ & $<.001$ \\
\hline Cardioversion during hospitalization & $56(31.8)$ & $39(11.1)$ & $3.05(2.22-4.21)$ & $<.001$ \\
\hline Reoperation due to bleeding & $14(8.0)$ & $33(9.4)$ & $0.85(0.49-1.48)$ & .560 \\
\hline Delayed ventilation & $16(9.1)$ & $33(9.5)$ & $1.15(0.69-1.92)$ & .596 \\
\hline Acute de novo dialysis & $2(1.1)$ & $5(1.4)$ & $1.15(0.29-4.64)$ & .846 \\
\hline
\end{tabular}


TABLE E2. Continued

\begin{tabular}{|c|c|c|c|c|}
\hline & AF after discharge $(n=176)$ & No AF $(\mathbf{n}=353)$ & HR $(95 \%$ CI $)$ & $P$ value \\
\hline In-hospital death & $1(0.6)$ & $5(1.4)$ & $2.11(0.29-15.18)$ & .457 \\
\hline Length of hospital stay & $8.0(7.0-12.0)$ & $8.0(7.0-11.0)$ & $0.98(0.96-1.01)$ & .215 \\
\hline
\end{tabular}

